Uluslararası Mühendislik

FAKÜLTESI

Araştırma ve Geliştirme Dergisi

UMAGD, (2020) 12(1), 251-264.

International Journal of

Engineering Research and

Development

10.29137/umagd.620761

Cilt/Volume:12 Sayı/Issue:1 Ocak/January 2020

Araştırma Makalesi / Research Article

\title{
Finite Element Analysis of Laminated Glass Plates Subjected to Impact Loading
}

\author{
Ebru Dural $^{1}$ \\ ${ }^{1}$ Adnan Menderes Üniversitesi, Mühendislik Fakültesi, İnşaat Mühendisliği Bölümü, 09100, Aydın, TURKEY
}

Başvuru/Received: 16/09/2019

Kabul / Accepted: 20/12/2019

Çevrimiçi Basım / Published Online: 31/12/2019

Son Versiyon/Final Version: 31/01/2020

\begin{abstract}
Laminated glass is a type of glass formed by placing an intermediate layer, called PVB (polyvinyl butyral), between two or more glass plates. The joining of the layers takes place with the aid of heat and pressure. As a result of the processes carried out, the adhesion of the PVB appears and the layers appear as a single glass. Due to this feature of the intermediate layer, even if the glass breaks in the face of earthquake, storm, impact and similar events, it does not scatter around. As a result of the fracture, a spider web-like appearance is formed. Nevertheless, it is the least damaging of consequences such as the damage of living things. Laminated glass was first used in the automotive industry in 1914. Recently, there has been a noticeable increase in the use of many areas, especially in construction industry. The purpose of this work is to analyze effect of impact loads on mechanical behavior of laminated glass plates using finite element method. Laminated glass plate is analyzed as fixed supported. Results are presented in figures. As result of study, it is observed that geometry of impactor and the interlayer material are the factors that effect impact behavior of laminated glass unit.
\end{abstract}

Key Words

"Finite element method, Impact load, Laminated glass, Nonlinear behavior" 


\section{Introduction}

Laminated glass was first used in the automotive industry in 1914. It consists of two or more thin glass layers and an intermediate layer which connects them as shown in Figure 1. Laminated glass provides strength against impact by revealing the adhesion feature with PVB interlayer. The intermediate layer keeps the broken glass parts together and prevents them from scattering. In this way, people are less likely to be harmed. The laminated glass plays an important role to provide protection from natural dis asters such as earthquake, hurricanes and external forces arising from living things. In addition, UV rays are less permeable, which prevents sunlight from harming human health. Because of the mentioned properties, it has a history and future that goes back to the building sector. Nowadays, it continues to be produced using intermediate layers of different colors and thicknesses.

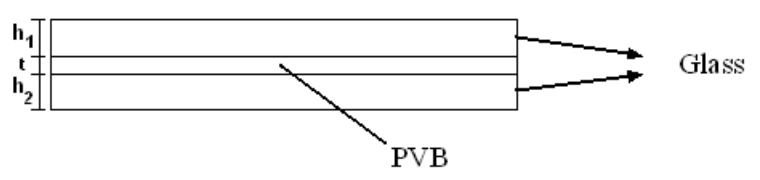

Figure. 1. Laminated glass.

Laminated glasses exhibit highly nonlinear behavior under any loading because they can undergo deformation even under their own weight. Owing to this stresses develop on the mid-plane of the laminated unit and the differential equations, governs their behavior, become nonlinear. Also the big difference between elasticity modulus of the layers forming the laminate glass causes nonlinearity.

Impact is a common problem in construction, military, aerospace and automotive industries for brittle materials. Factors like, impact force, impact velocity, contact duration, displacement, acceleration, impact energy and energy absorption should be considere do evaluate the impact behavior. Current study aims to analyze behavior of laminated glass unit subjected to impact. The resistance capacity of laminated glass unit subjected to windborne debris impact is very high. Under impact loading the outer glass layer shatters while the inner glass layer remains unsheltered. The polyvinyl butyral interlayer absorbs the impact energy and keeps the glass layers in contact, thereby prevents damage, injury and even death of people.

In this study, different impactor geometries were applied to laminated glass under different velocities and the problem is modeled employing finite element method. The mechanical effects of the impact load on the laminated glass are analyzed. As a result, graphs of force, stress and deformation are obtained.

\section{Literature Review}

Usage of laminated glass in building industry has started to gain momentum and for this reason studies about them are increasing. In the last decades many researchers conducted studies to analyze the behavior of laminated glass. Most of the researchers performed experimental analysis of laminated glass units. [Hooper (1973), Behr et. al. (1985), Behr et. al (1993), Behr et. al. (1986)]. Besides the mentioned experimental studies there are limited theoretical study about the performance of laminated glass. Researchers, over the past three decades have conducted numerical studies in order to model the behavior of laminated glass. [Vallabhan et. al.(1993), Asik (2003), Foraboschi (2012), Asik and Tezcan (2005), Foraboschi (2007), Galuppi and RoyerCarfagni( 2012) ].

Understanding the breakage mechanism of glass, subjected to falling objects impact, and effect of impact loading to the use and design of glass unit is a fascinating subject for several researchers. Therefore the literature contains many experimental and analytical research on the impact behavior of laminated glass unit.

Minor and Reznik (1990) analyzed effect of glass type and thickness on the impact behavior of monolithic glass unit. They observed that breakage resistant of annealed monolithic glass unit was less than that of fully tempered monolithic unit. Behr and Kramer (1996) conducted a study to summarize impact behavior of laminated glass units. They concluded that at $129 \mathrm{~km} / \mathrm{h}$ impact test velocity breakage probability of fully tempered glass is higher than that of heat strengthened glass.

Pantelides et.al (1993) analyzed post breakage performance of heat strengthened laminated glass systems subjected to impact loading. In 1996 Behr and Kremer conducted impact tests to understand the effect of interlayer thickness and glass type on the breakage of inner glass sheet. They observed that as the thickness of interlayer is increasing the breakage probability of inner glass subjected to wind borne debris impact decreases.

Flocker and Dharani (1997) analyzed laminated glass unit subjected to low velocity missile impact using finite element method. They used finite element method to analyze effect of glass geometry on the impact behavior of laminated glass unit. They concluded that, laminated glass consists of three layers, shows the best resistance to impact. They observed that with respect to thick outer ply, thin outer ply provides better impact resistance and reduces the probability of undesired interlayer debonding.

Behr et al. (1985) performed experimental studies about the low missile impact behavior of laminated glass to confirm the outcomes of finite element model developed by Flocker and Dharani [15]. The results are found quite close to each other. 
Saxe et.al (2002) developed a model for sacrificial-ply-laminated glass units subjected to wind pressures and windborne debris impact. They observed that as the size and mass of the impactor is increasing the velocity which is necessary to break the innerglass ply reduces and the kinetic energy which cause to fracture increases.

Timmel et. al. (2007) developed a computational model using explicit finite element model to impact performance of laminated glass unit. They performed experiments in order to validate their model.

Karunarathna (2013) conducted analytical and numerical method to analyze impact response of laminated and monolithic glass units subjected to low velocity missile impact.

Wang et al. (2017) compared four numerical method which used to analyze fracturing process of brittle glass. These methods are based on continuum and discontinuum categories. Also they compared the FEM and DEM models by experimental results for glass unit subjected to high speed and oblique impact tests.

Yuan at al. (2017) developed an analytical model to analyze low velocity impact behavior of rectangular laminated glass which shows non linear behavior and glass fracture. They observed that laminated glass bonded by stiffer interlayer material leads to greater contact force and less transverse displacement.

\section{Material and Method}

\subsection{Finite Element Modelling}

From the above explanations, it may be concluded that many studies have been conducted for the impact analysis of laminated glass units. In this study, a finite element method based software, ABAQUS, is employed to model and analyze the effect of different missile types, different interlayer material on the dynamic impact behavior of laminated glass unit. Many of the physical problems in the nature may be represented by partial differential equations. Some of these equations may be very complicated to solve using mathematical methods. Finite element method is a very useful tool used to solve the mentioned complicated differential equations. In the finite element method the unit is divided of small elements and for each of mentioned small elements an approximation is made.

Inner and outer glass plies, PVB interlayer and impactor are modeled as different parts. The glass layers and interlayer are modeled using three dimensional deformable options. The laminated glass unit considered has dimensions of $1 \mathrm{~m} \times 1 \mathrm{~m}$ (see Figure 2 ). Each glass ply has a thickness of $6 \mathrm{~mm}$. The interlayer thickness is $0.76 \mathrm{~mm}$. The total thickness of the unit is $12.76 \mathrm{~mm}$. The beam materials, glass and interlayer, are assumed as completely elastic and obey Hooke's law. The Young's modulus and Poisson's ratio of glass are taken to be $74.4 \mathrm{GPa}$ and 0.24 , respectively. Young's modulus and Poisson's ratio of the PVB interlayer are taken as 6.3 MPa and 0.4, respectively. For EVA interlayer Young's modulus and Poisson's ratio of the PVB interlayer are taken as 15.7 $\mathrm{MPa}$ and 0.48 , respectively. The density of glass, PVB and EVA are specified to $2500 \mathrm{~kg} / \mathrm{m}^{3}, 1100 \mathrm{~kg} / \mathrm{m}^{3} \mathrm{and} 943 \mathrm{~kg} / \mathrm{m}^{3}$, respectively. The three dimensional model is generated and solved with ABAQUS. To perform large deformation analysis "geometric nonlinearity" option is used. The bond between the interlayer and glass plies is assumed to be perfect with no debonding or slipping during impact. A hexahedral element and sweep mesh pattern is applied for mesh of laminated glass unit. Twenty node quadratic brick elements (C3D20R) are used in meshing because the program gives more accurate results where large faster convergence. Biased mesh is used in the developed model since fine mesh is required to obtain more accurate results at the neighborhood of impact area. For this reason, unstructured mesh is used in the developed model. In the literature some researchers like Kim et.al (1997) used unstructured mesh pattern in their studies.

An analysis is conducted to obtain optimum number of mesh elements required for convergent solution. Result of conducted mesh analysis can be seen from Figure 2 for laminated glass unit subjected to spherical impactor. The laminated glass unit has one mesh for each layer along the thickness direction. The approximate element size is $0.0075 \mathrm{~m}$. and the laminated unit is divided into nearly 63000 elements to obtain convergence while the impactor is divided nearly 13000 elements. The laminated glass plate and impactor element arrangements are illustrated in Figure 4. It is well known that the mesh density plays an important role in the simulation. A refine mesh technique is applied in the contact zone since the role of mesh density plays an important role in the analysis. In order to create a finer mesh around the impact region a circular partition section is used at the center of plate unit. The boundaries are modeled as fixed edge. At the fixed ends of the unit, vertical and horizontal degrees of freedom of all the nodes of the unit are set to be zero. To define the initial condition, predefined field option is used instead of boundary condition option. In order to prevent the initial conditions like displacement and velocity stay constant during the simulation instead of boundary condition option, predefined field option is used. 


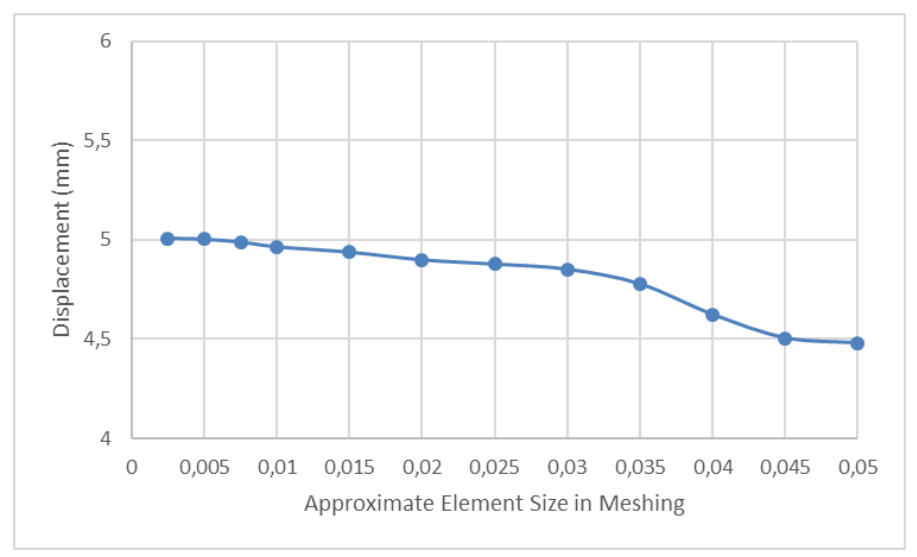

Figure. 2. Approximate element size versus Displacement

Two different types of impactors are used in the current study. Cylindrical and spherical impactors are modeled as 3D solid with mass of $1 \mathrm{~kg}$. The behavior of impact object is assumed as a rigid body during the analysis. In other words, during the impact process the amount of deformation will be neglected. The whole rigid impactor is controlled by a single point called as reference point and the impact velocity are also assigned at the defined reference point in this simulation.

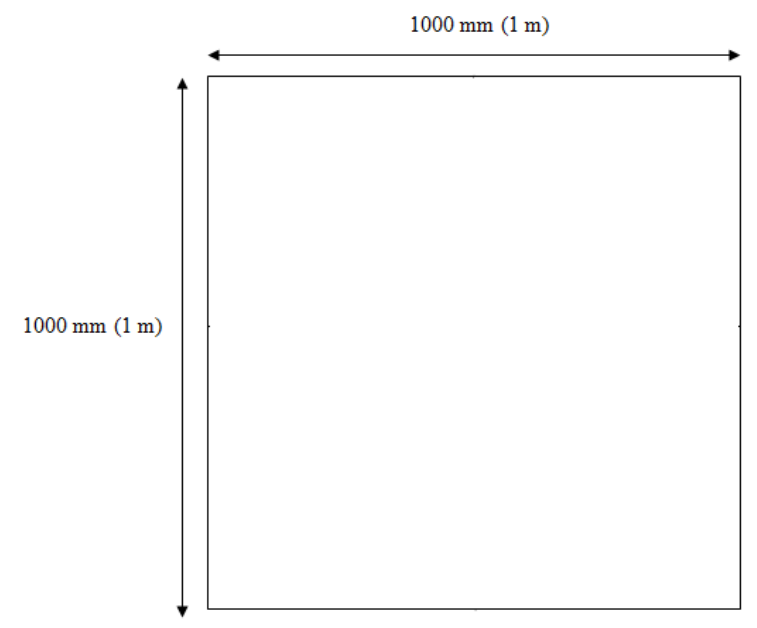

Figure. 3. Plate model

Impact problems may be solved using implicit or explicit algorithms which are available in the used package program. In this study the model is developed using explicit scheme.

In the literature, the impactor modelled using three different approaches:

- The material property may ignored and the impactor may be modelled as fully rigid.

- The impactor may be modelled as rigid body with material property,

- The impactor may be modelled as deformable with assigned property.

In the current study the impactor is modeled as fully rigid. Impact is a phenomenon which occurs in a very short time duration. Because of this reason, impact responses like displacement, stress, forces, energy dissipation and damage vary with time. Although the deformable model leads more realistic results many researchers Liu and Liaw [19] modeled it as rigid body because of the negligible deformation of impactor.

To analyze the influence of impactor geometry two different types of impactors such as spherical and cylindrical are investigated in the current study. The spherical impactor and flat ended cylinder mass diameters are $0.05 \mathrm{~m}$. The mass of projectile is $1 \mathrm{~kg}$ and period is 0.0001 seconds. To define boundary conditions of the impactor except the translation in vertical direction the translations and rotations in other directions are set to be zero. Since the impactor is modeled as rigid a reference point is defined to specify the mass of the impactor. Predefined field option is used to specify the velocity of impactor. The impact velocity range of the projectiles are $0-50 \mathrm{~m} / \mathrm{s}$ in the analyzes. The velocity increment is $5 \mathrm{~m} / \mathrm{s}$ in the analysis. 


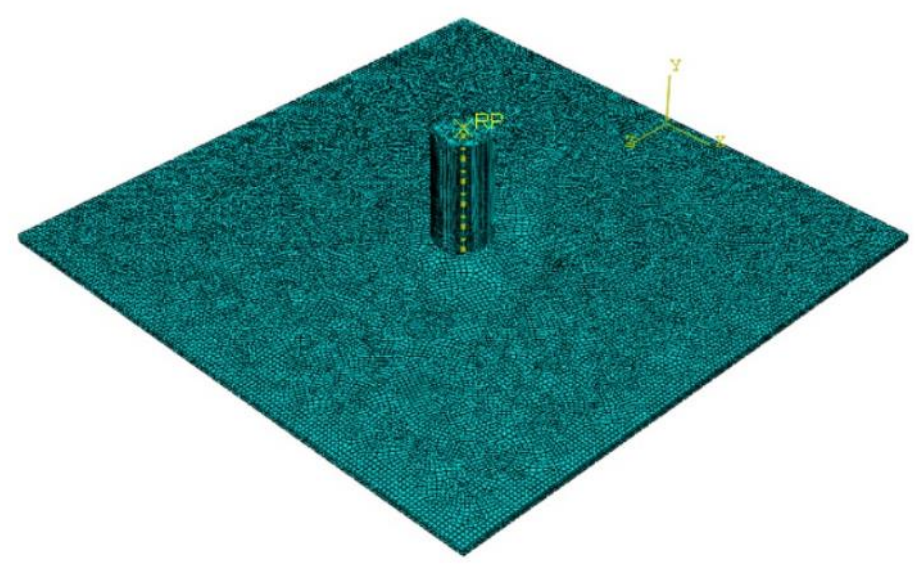

Figure. 4. Mesh of laminated glass and cylindrical impactor.

\section{Results}

The main purpose of this paper is to analyze effect of impactor geometry, velocity and different interlayer materials on the impact behavior of laminated glass plate structures. There are many different types of interlayer on the laminated glass market. Ethylene vinyl acetate (EVA) and polyvinyl butyral (PVB) are the most common binding material used in laminated glass market. In most of the earlier work PVB is used as the bonding material in glazing industry but usage of EVA as bonding material show dramatic increase because of its some advantageous properties. In the current research study, to investigate the effect of interlayer material on the behavior of laminated glass subjected to the impact loading two different types of interlayer, PVB and EVA, are considered. Also impact response of laminated glass is studied for various impactor geometries. Cylindrical and spherical impactors are used in this study. Schematic representation of laminated glass analyzed in this study, is given in Figure 5. Figure 5.a and Figure 5.b show the laminated glass subjected to the spherical and cylindrical impactor geometry, respectively. To consider the effect of interlayer type on the impact behavior of laminated glass plate the problem is solved for laminated glass unit with interlayer EVA as shown in Figure 5.c and Figure 5.d.
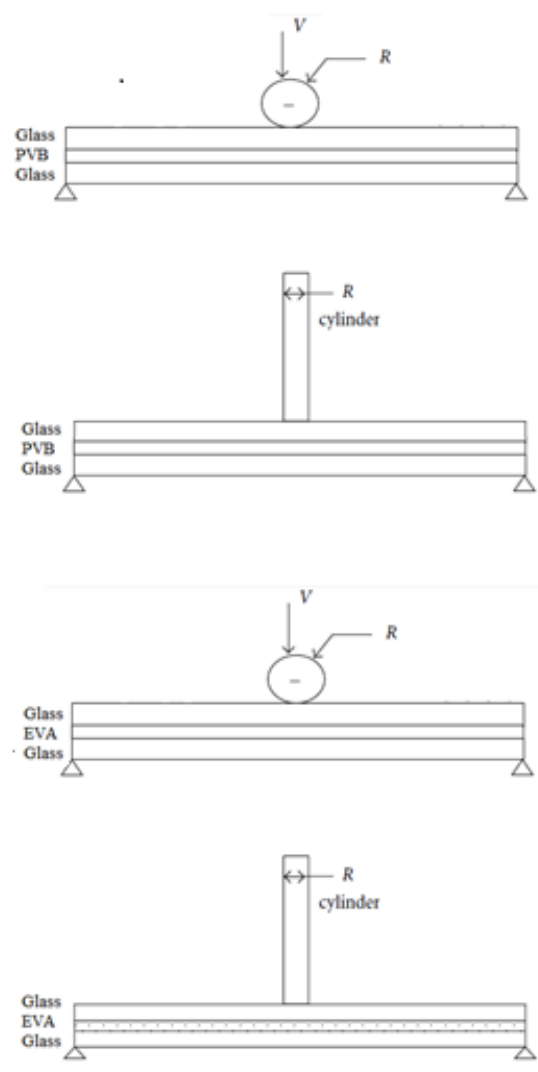

Figure. 5. Laminated glass subjected to a) spherical impactor b) cylindrical impactor c) laminated glass bonded by interlayer EVA subjected to cylindrical impactor d) laminated glass bonded by interlayer EVA subjected to spherical impactor. 
The displacements and stresses from the finite element program are saved and imported into EXCEL to plot diagrams. Figures 6 and 7 are plotted to analyze the behavior of laminated glass subjected to spherical impactor. It can be observed from the figures that as the velocity is increasing the displacement values increase linearly while maximum principal stress values increase nonlinearly. Displacements and stresses are maximum at the center of unit. The nonlinear behavior can be observed from the figures. As can be seen from Figure 8 maximum principal stress contours get their maximum values at the center of plate unit.

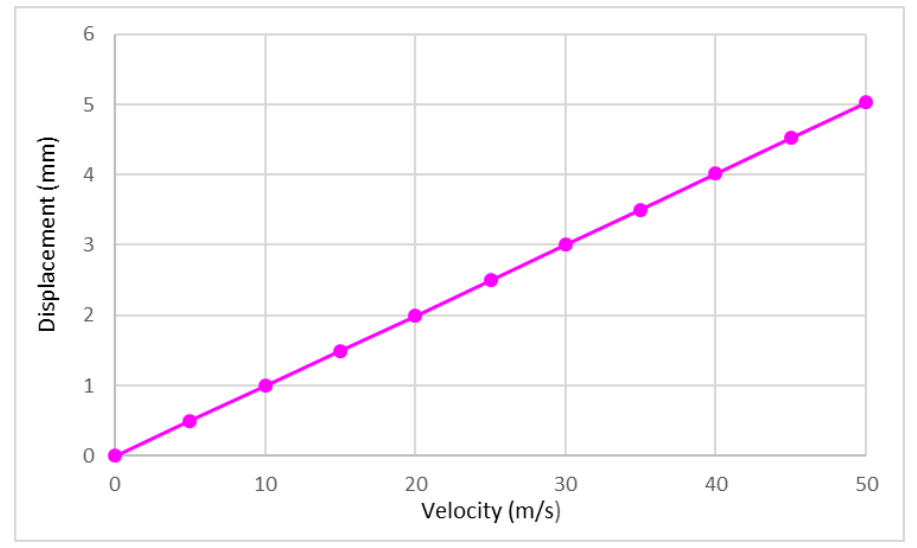

Figure. 6. Maximum displacement versus velocity for laminated glass subjected to spherical impactor.

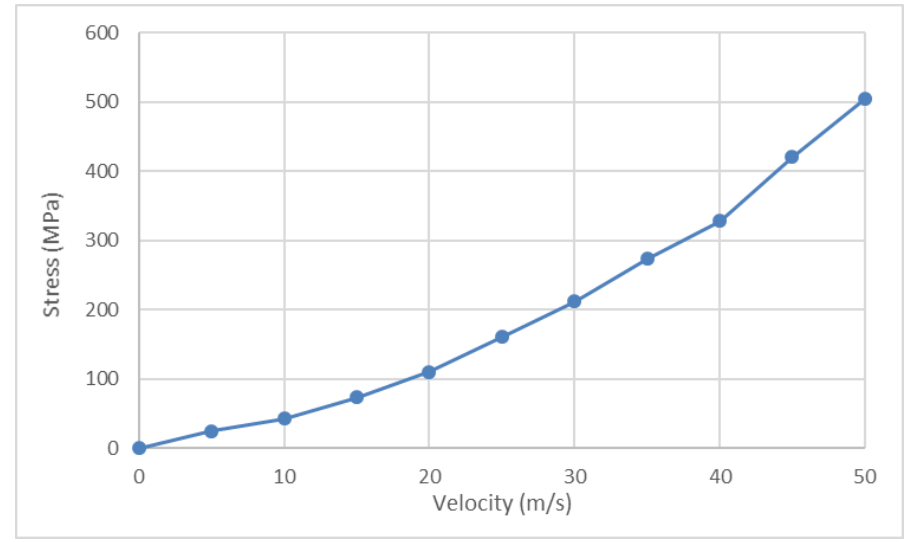

Figure. 7. Maximum stress versus velocity for laminated glass subjected to spherical impactor.

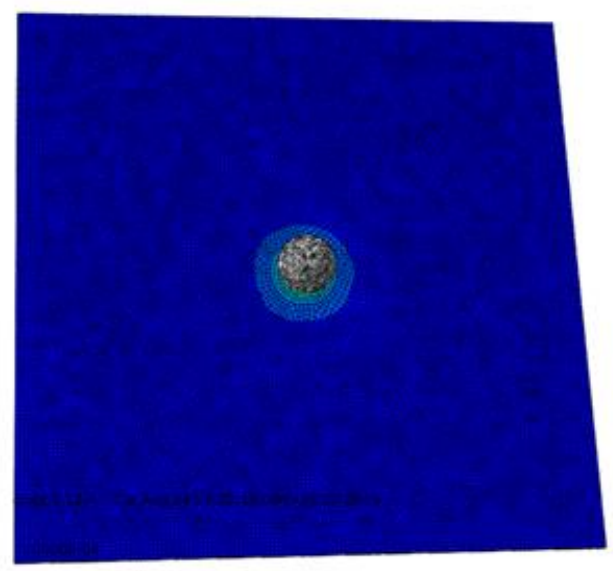

Top View

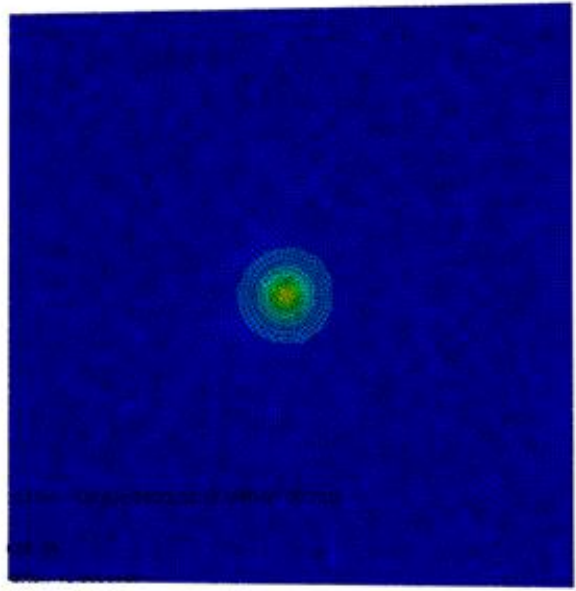

Botton View

Figure. 8. A view of contours of principal stress acquired from ABAQUS for laminated glass subjected to spherical impactor.

Behavior of laminated glass plate subjected to the cylindrical impactor are given in Figures 9 and 10. While the stress values of spherical and cylindrical impactor are nearly equal to each other for $40 \mathrm{~m} / \mathrm{s}$ velocity, the stress values of spherical impactor are smaller than those of cylindrical impactor for other velocities. Displacements show reverse pattern. The displacements of cylindrical impactor are nearly 1.7 times higher than those of spherical ones. Since the mass of the rigid impactors are same we can say that the geometry of impactor affects the impact behavior of laminated glass unit. It is clear from above figures that when laminated unit, bonded with PVB, subjected to cylindrical impactor it deflects more than the unit subjected to spherical impactor.Figure 11 
shows the distribution of principal stress contours on the plate surface. The principal stresses get their maximum value at the center of the outer glass surface.

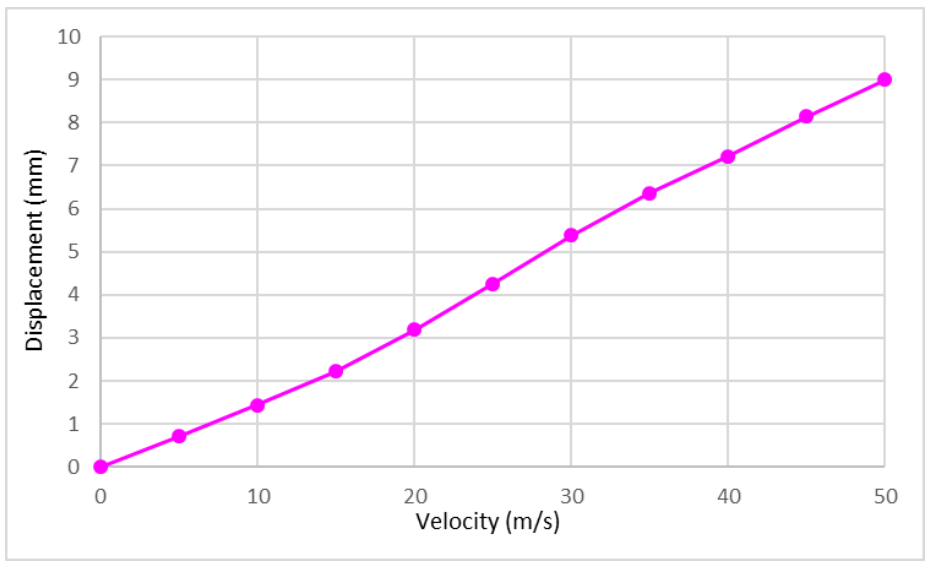

Figure. 9. Maximum displacement versus velocity for laminated glass subjected to cylindrical impactor.

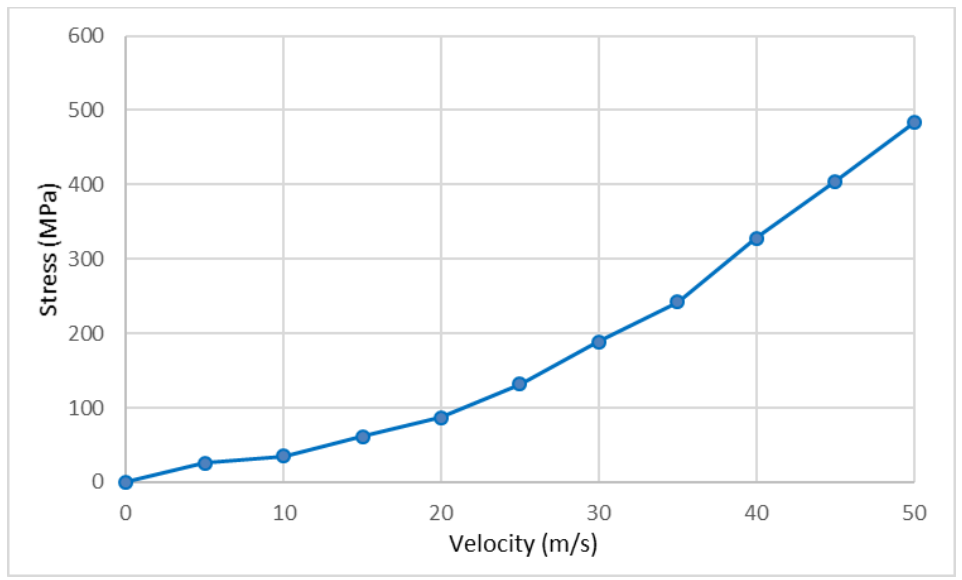

Figure. 10. Maximum stress versus velocity for laminated glass subjected to cylindrical impactor.

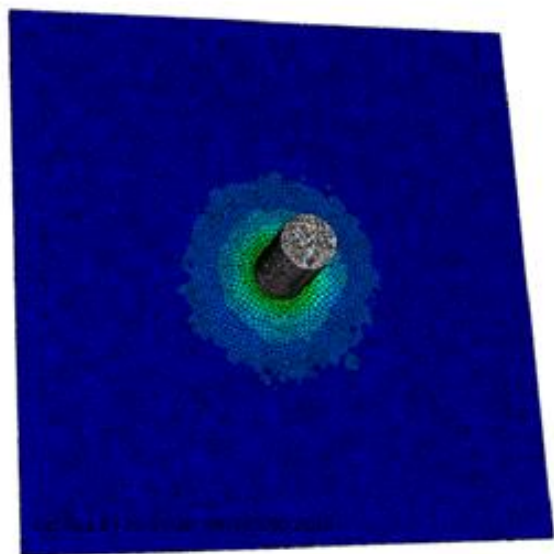

Top View

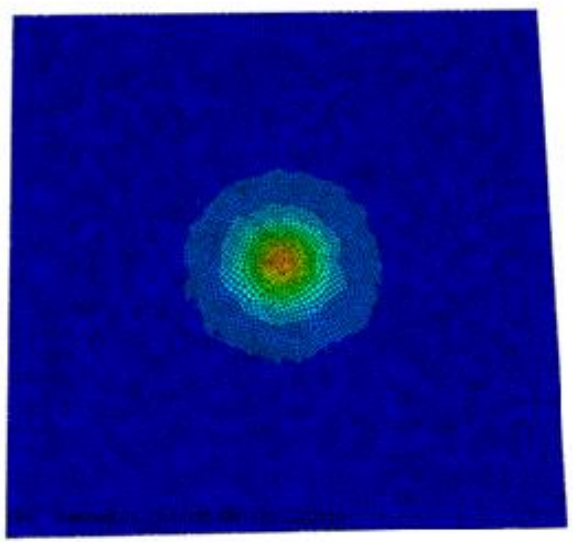

Botrom View

Figure 11. A view of contours of principal stress acquired from ABAQUS.

Laminated glasses contain two glass panes joined by a visco elastic interlayer. There are different types of interlayers used in lamination process. In order to analyze the effect of interlayer material on the behavior of laminated glass plate subjected to impact loading two types of interlayer, ethylene vinyl acetate film (EVA) and polyvinyl butyral (PVB), are used in the current study. Figures $12-13$ and 15 - 16 are plotted to illustrate the displacement and stress values for laminated unit, bonded with EVA, subjected to cylindrical and spherical impactor, respectively. It is observed from the below figures that displacement and stress values of laminated glass unit which contains EVA as binding material are greater than those of contain PVB as binding material. It may be concluded that impact resistance of PVB interlayer are greater than that of EVA. Figures 14 and 17 illustrate the principal stress contours on the plate surface for laminated unit subjected to cylindrical and spherical impactor, respectively. As we mentioned above, principal stress of laminated glass unit, bonded with PVB, are maximum at the center of laminated glass plate. The same trends also can be observed for the laminated glass bonded with EVA. 


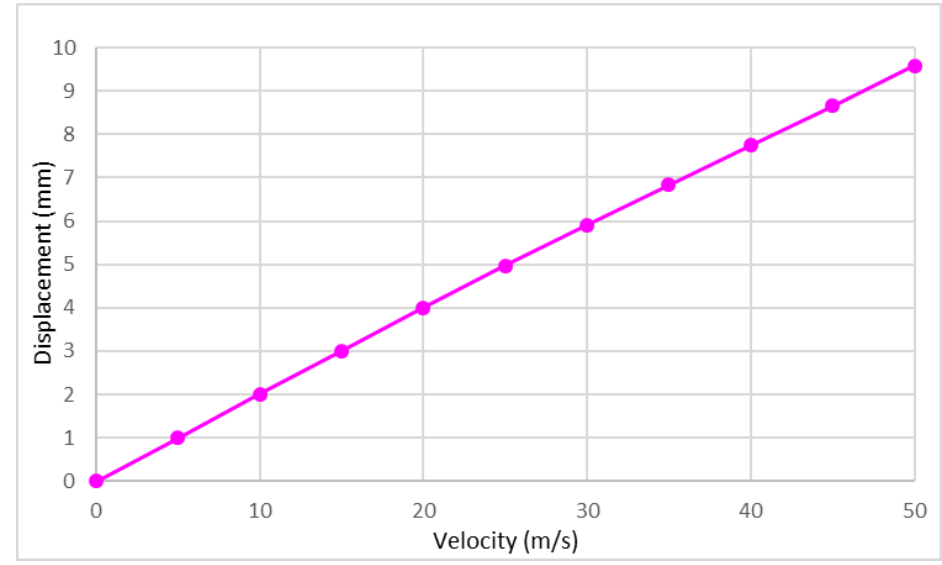

Figure. 12. Maximum displacement versus velocity for laminated glass, contains EVA as binding material, subjected to cylindrical impactor.

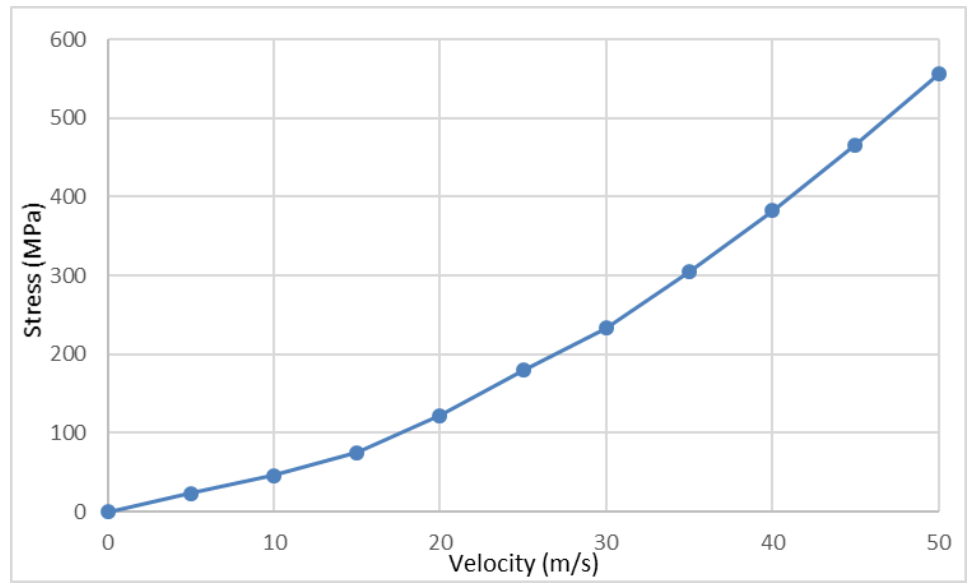

Figure 13. Maximum stress versus velocity for laminated glass contains EVA as binding material, subjected to cylindrical impactor.

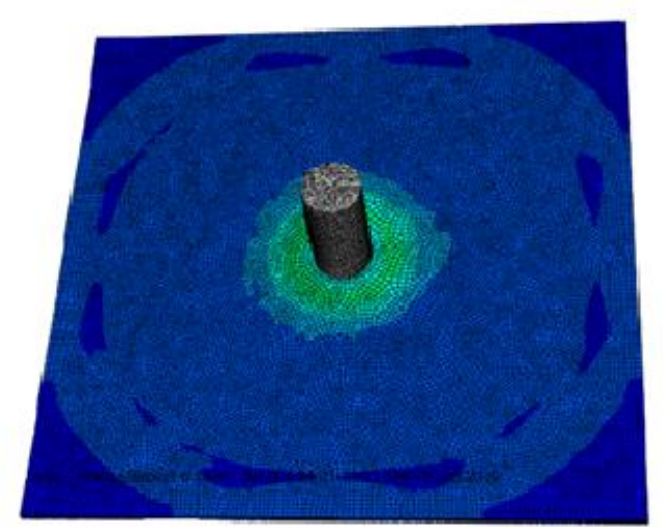

Top. View

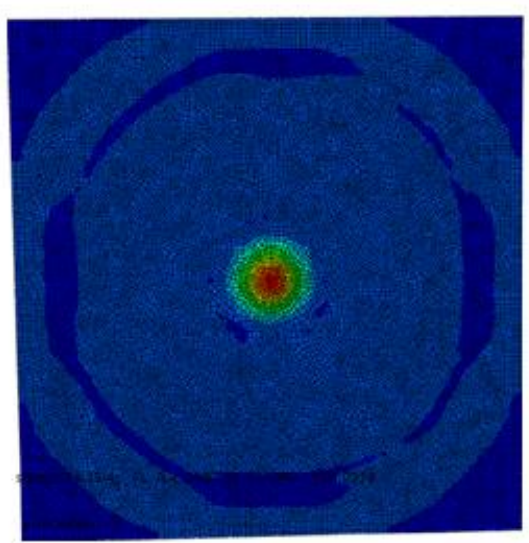

Bomax View

Figure. 14. A view of contours of principal stress acquired from ABAQUS for laminated glass contains EVA as binding material.

Behavior of laminated glass which contains EVA as interlayer material subjected to spherical impactor may be analyzed from the figures given below. Displacement and stress values for varying velocities are plotted in Figures 15 and 16, respectively. It is observed from the figures that stress and deflection values of laminated glass unit which contains EVA as binding material are greater than those of contain PVB as binding material. It may be concluded that impact resistance of PVB interlayer are greater than that of EVA. Above figures present that, displacement and stress values of laminated unit, bonded with EVA, is greater when it is subjected to cylindrical impactor. 


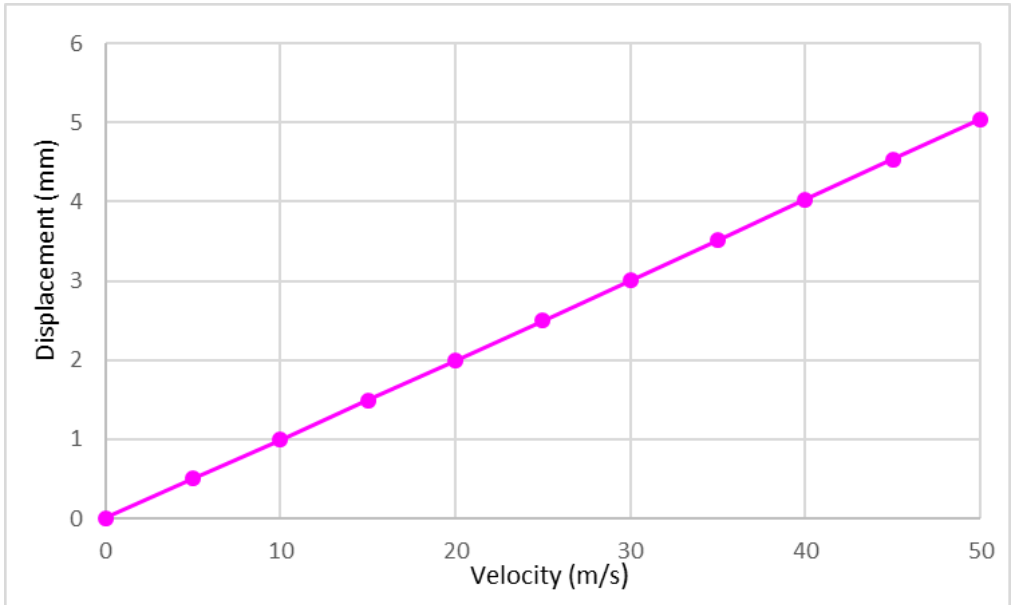

Figure. 15. Maximum displacement versus velocity for laminated glass, contains EVA as binding material, subjected to spherical impactor.

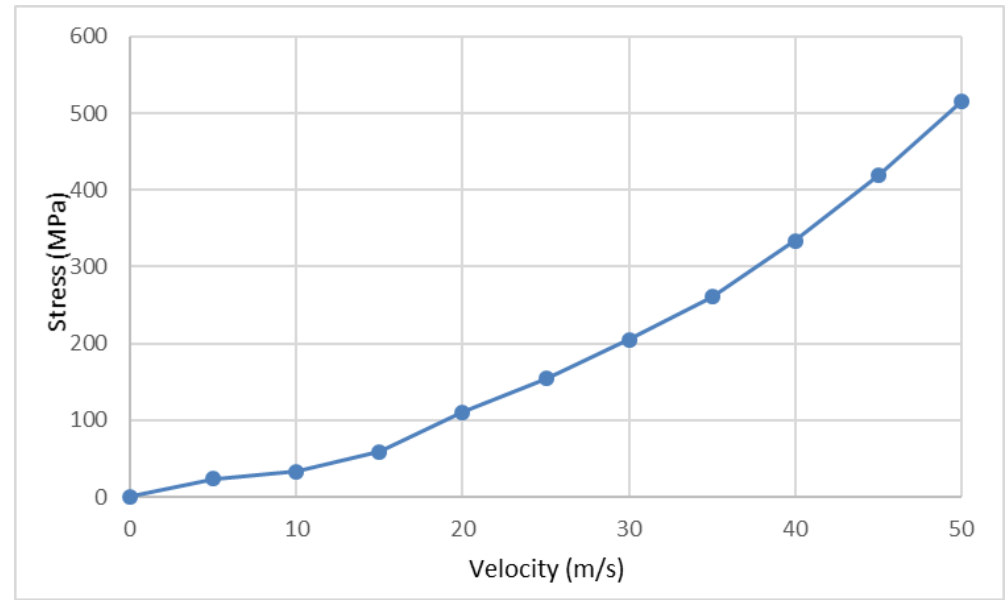

Figure. 16. Maximum stress versus velocity for laminated glass contains EVA as binding material, subjected to spherical impactor.

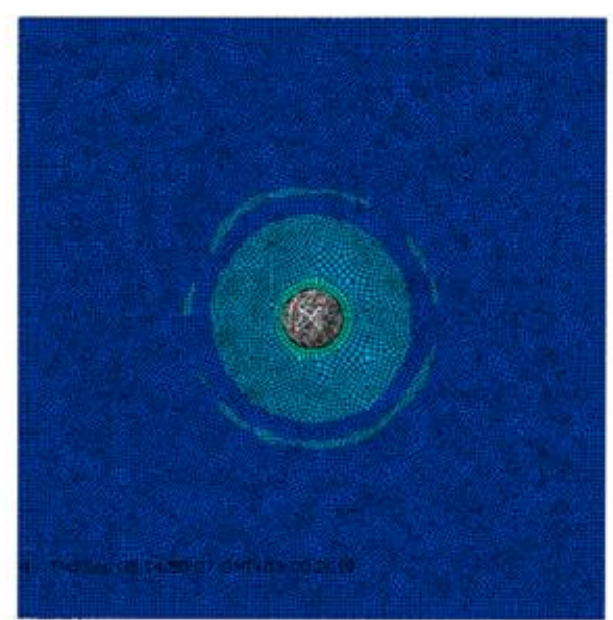

Top View

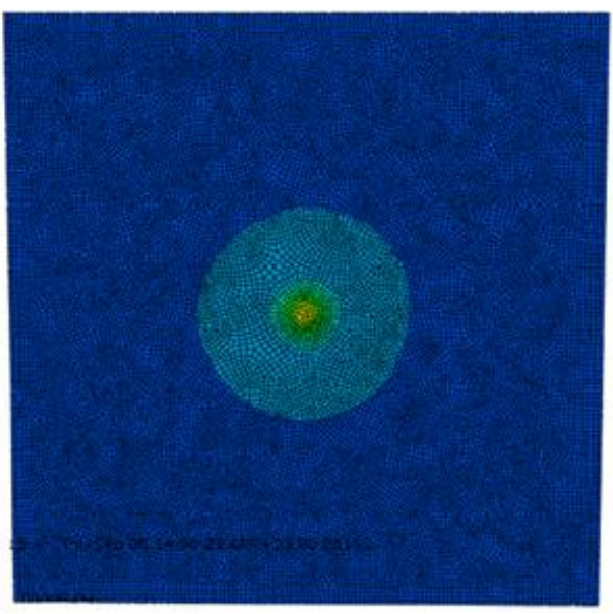

Botrom View

Figure. 17. A view of contours of principal stress acquired from ABAQUS for laminated glass contains EVA as binding material.

Because of the importance of mesh density a partition is created at the contact zone and refined mesh technique was applied in that contact zone. The mesh and element arrangement of each components is shown in Figure 18. Figures 19 and 20 are plotted to analyze stress and displacement time histories at the center of partition which is created at the contact region. Time history curves are plotted by considering $5 \mathrm{~m} / \mathrm{s}, 20 \mathrm{~m} / \mathrm{s}$ and $40 \mathrm{~m} / \mathrm{s}$ impact velocities. The stresses and displacements take their maximum value are maximum at the center of the contact zone. Time period is $100 \mu \mathrm{s}$. As the impact velocity is increasing, the peak displacement and stress response. The displacement increase for increasing time and they have unsymetric nature. It can be observed that the 
displacement of laminated glass unit significantly increase with increasing impact velocity. The peak stress and displacement responses increase with increasing impact velocity. Principal stresses take both positive and negative values for some velocities. The principal stresses of laminated glass unit subjected to cylindrical impactor take both positive and negative values for $40 \mathrm{~m} / \mathrm{s}$ velocity while they are positive for $5 \mathrm{~m} / \mathrm{s}$ and $20 \mathrm{~m} / \mathrm{s}$ velocities. The maximum stresses are compression at the top glass surface as excepted. It is also observed from the figure that as the impact velocity is increasing the value of maximum principal increases. On the time history curve there are jumps for some certain time values.

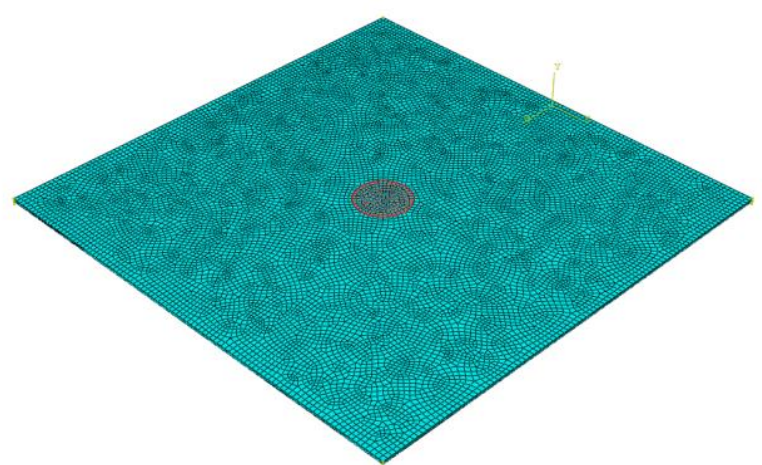

Figure. 18. Laminated glass plate and set created at the contact zone.

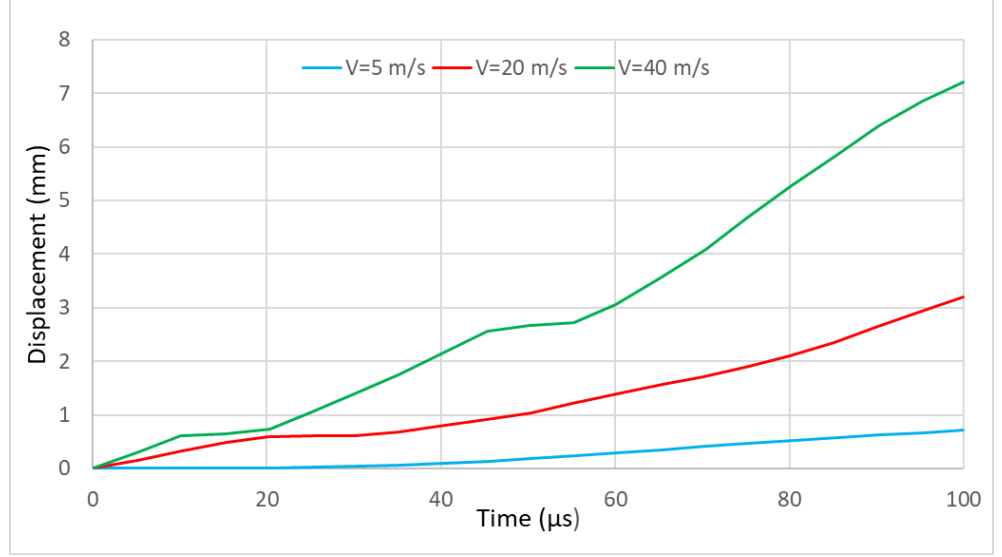

Figure. 19. Displacement time history for laminate glass plate subjected to cylindrical impactor.

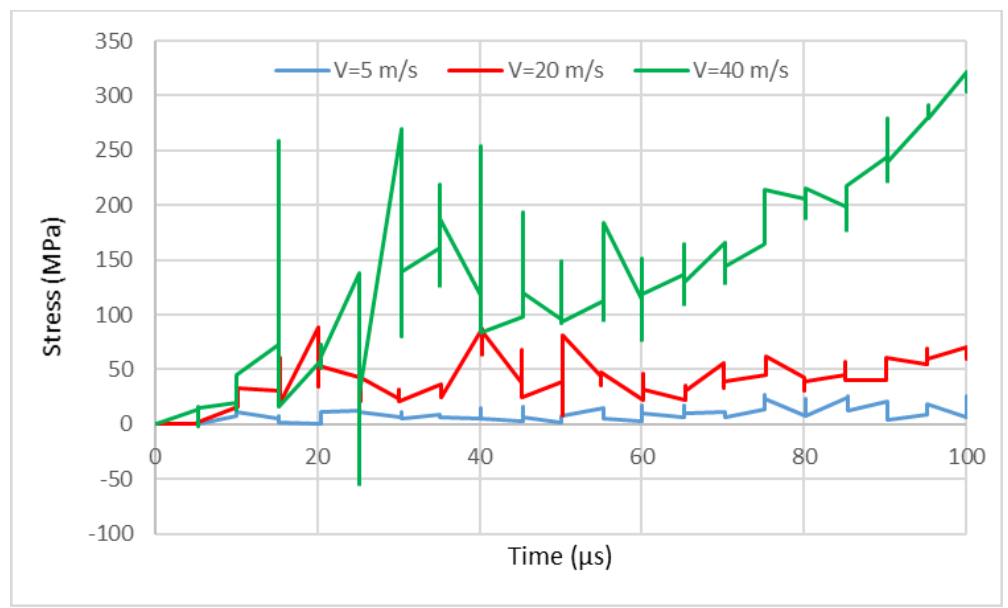

Figure. 20. Principal stress time history for laminate glass plate subjected to cylindrical impactor.

Figures 21 and 22 depict principal stress and displacement histories for laminated glass plate subjected to spherical impactor by considering $5 \mathrm{~m} / \mathrm{s}, 20 \mathrm{~m} / \mathrm{s}$ and $40 \mathrm{~m} / \mathrm{s}$ impact velocities. The impact duration for impact is $100 \mu$ seconds. It is observed from the figures that displacements and stresses take their maximum values between 0 and 0.0001 seconds. As time is increasing the peak value of displacements increase. While displacement-time history of laminated glass is subjected to cylindrical impactor is a smooth line; it is twisted for laminated glass unit subject to spherical impactor. Similar to the behavior of unit subjected to cylindrical impactor the principal stress curves of spherical impactors have jumps.

Figures 23 and 24 are plotted to observe variation of displacement and stress versus time for laminated glass with interlayer EVA subjected to cylindrical impactor while Figures 25 and 26 are plotted the same unit subjected to spherical impactor for $5 \mathrm{~m} / \mathrm{s}, 20$ 
$\mathrm{m} / \mathrm{s}$ and $40 \mathrm{~m} / \mathrm{s}$ impact velocities. It is clear from figures that the higher the velocity, the higher the maximum stress and displacement values. As can be seen from the figures that character of displacement- time history curves is depend on the geometry of impactor. While they are smooth for spherical impactor, they are twisted for cylindrical impactor. The principal stress-time history of laminated glass bonded with EVA subjected to cylindrical impactor shows some difference since sharp sudden drops are not observed from the stress curve for $20 \mathrm{~m} / \mathrm{s}$ and $40 \mathrm{~m} / \mathrm{s}$ velocities.

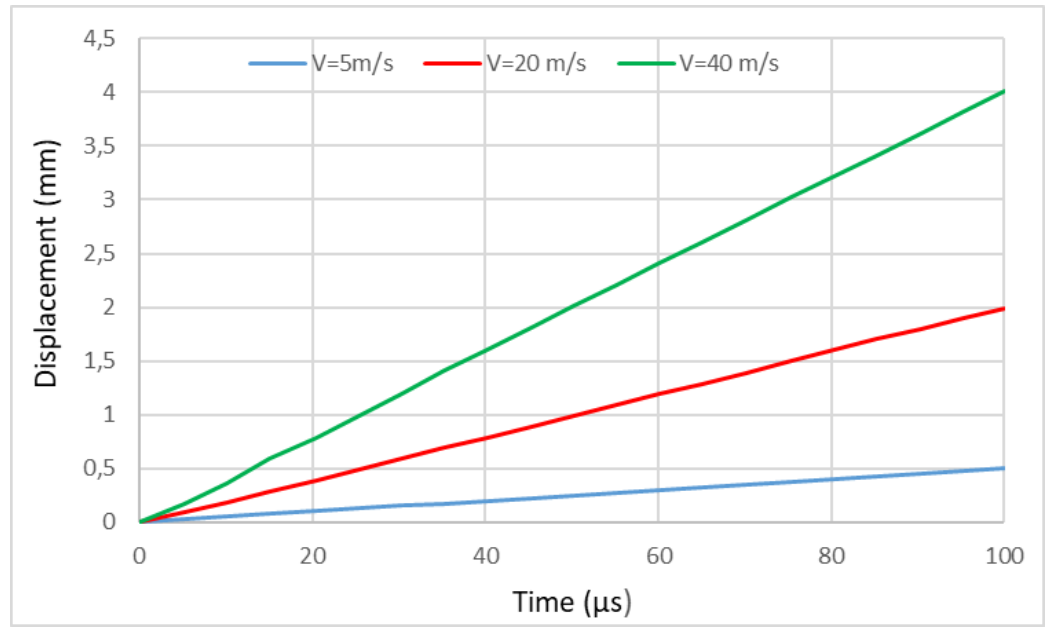

Figure. 21. Displacement time history for laminate glass plate subjected to spherical impactor.

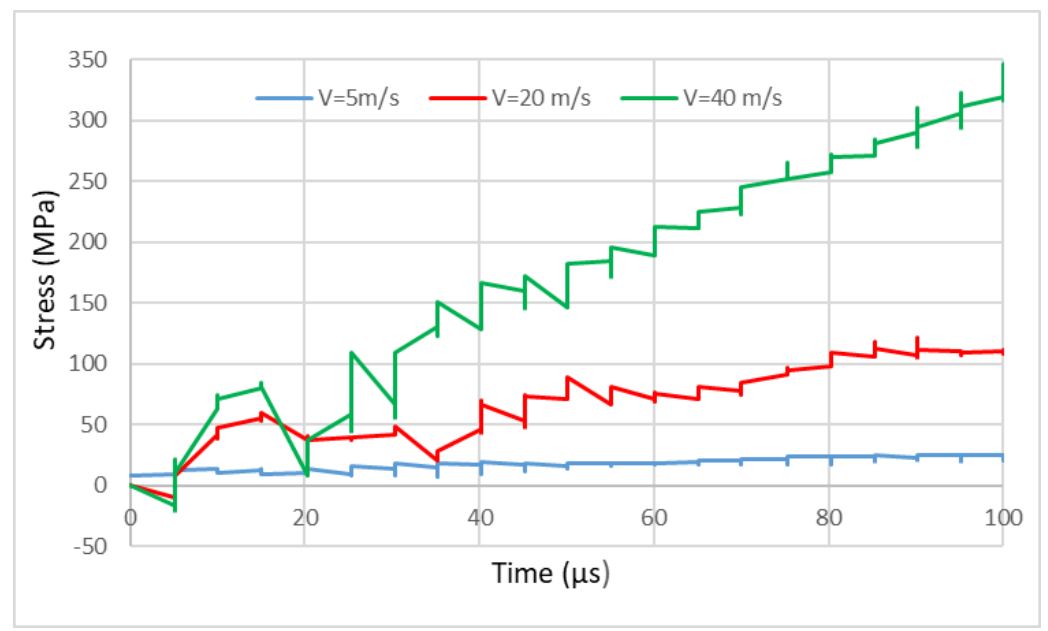

Figure. 22. Principal stress time history for laminate glass plate subjected to spherical impactor.

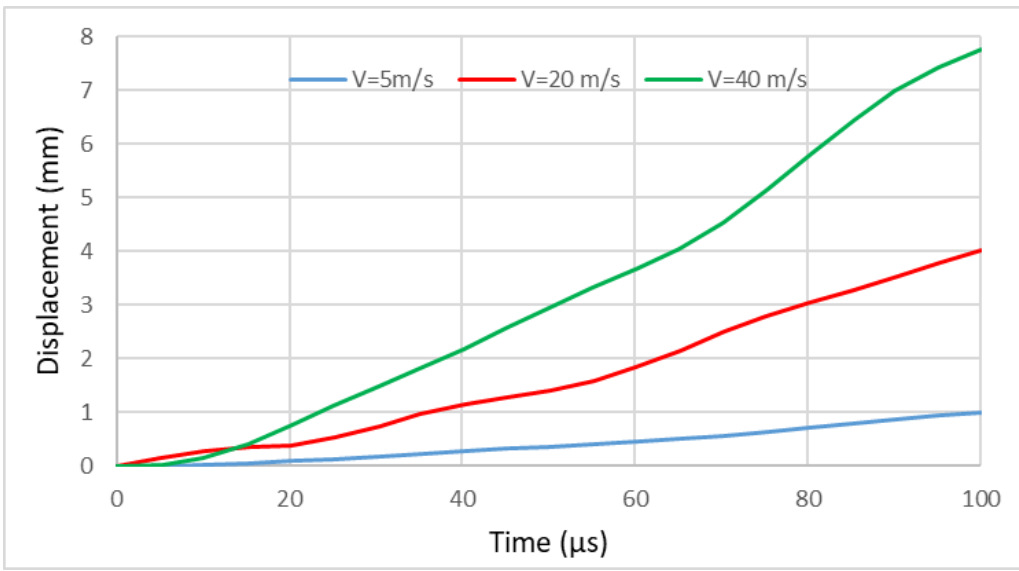

Figure. 23. Displacement time history for laminate glass plate with interlayer EVA subjected to cylindrical impactor. 


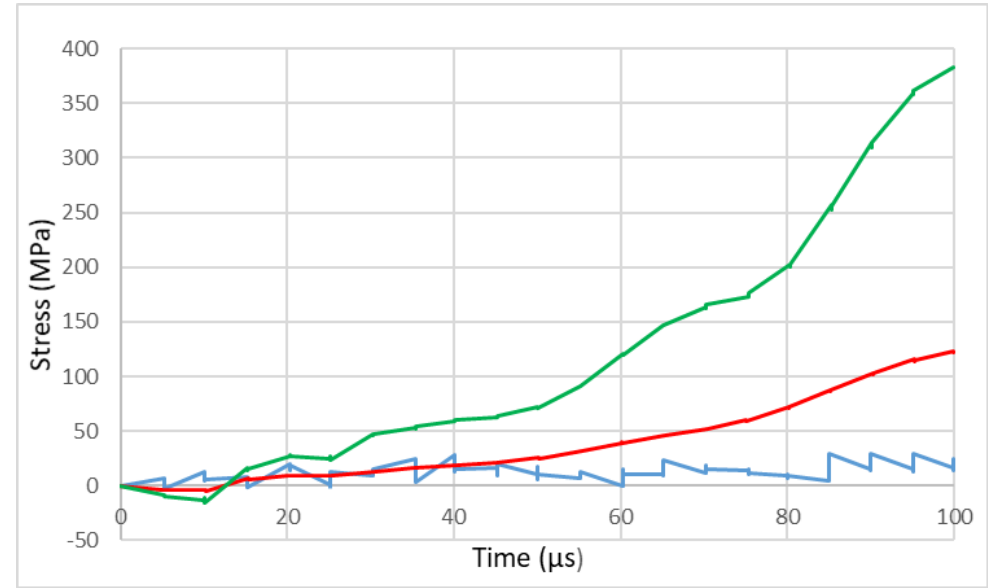

Figure. 24. Principal stress time history for laminate glass plate with interlayer EVA subjected to cylindrical impactor.

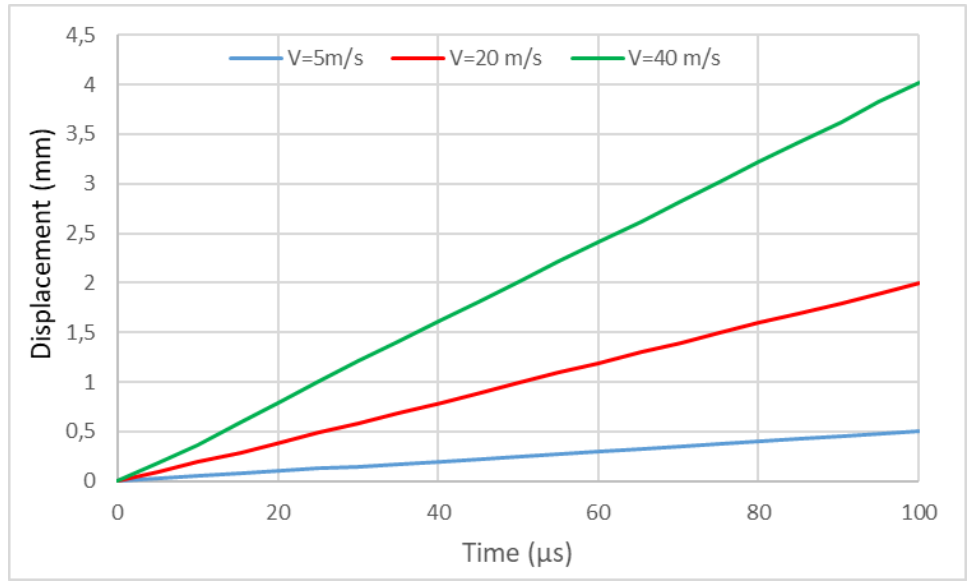

Figure. 25. Displacement time history for laminate glass plate with interlayer EVA subjected to spherical impactor.

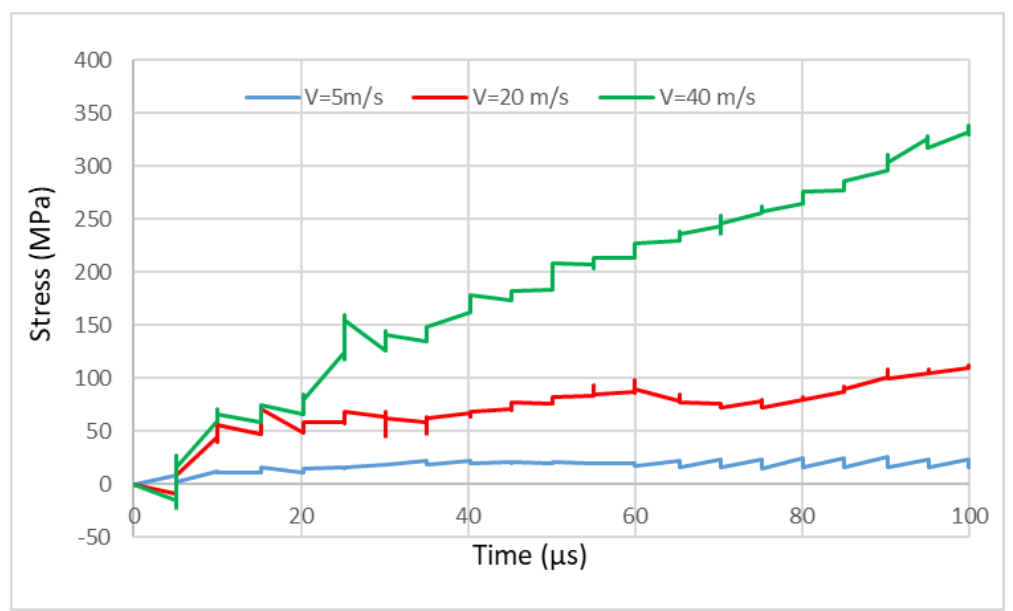

Figure. 26. Principal stress time history for laminate glass plate with interlayer EVA subjected to spherical impactor.

The internal energy is very important to prepare the system to a given state in real life. The amount of internal energy time history curves for laminated units subjected to cylindrical and spherical impactors are shown in Figures 27 and 28 , respectively. It is obvious from the figures that the laminated glass subjected to cylindrical impactor absorbs more energy than those subjected to spherical impactor. 


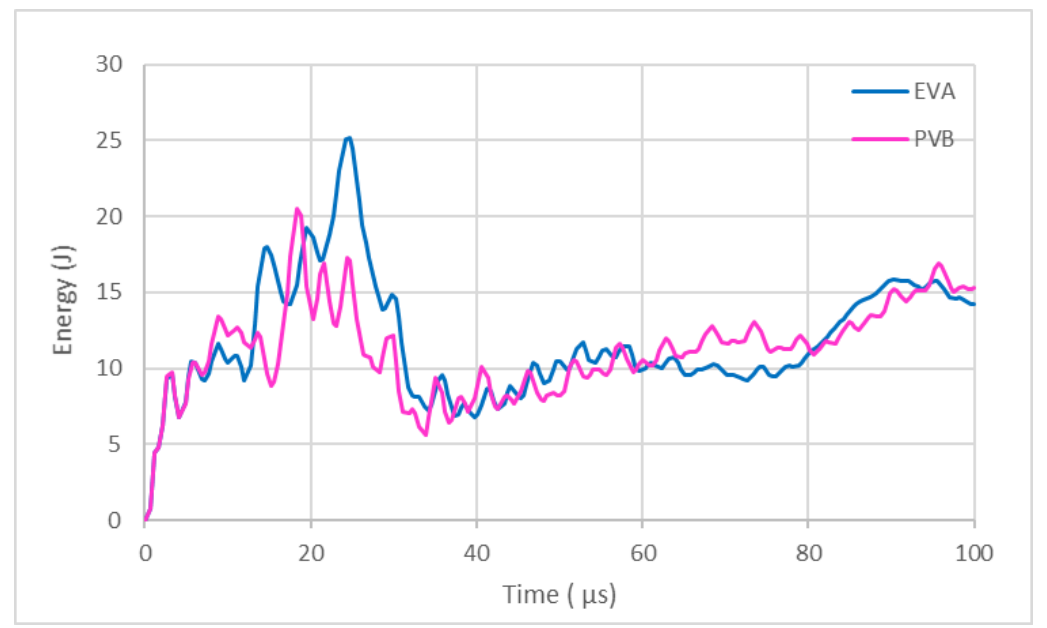

Figure. 27. Energy time history for laminate glass plate subjected to cylindrical impactor.

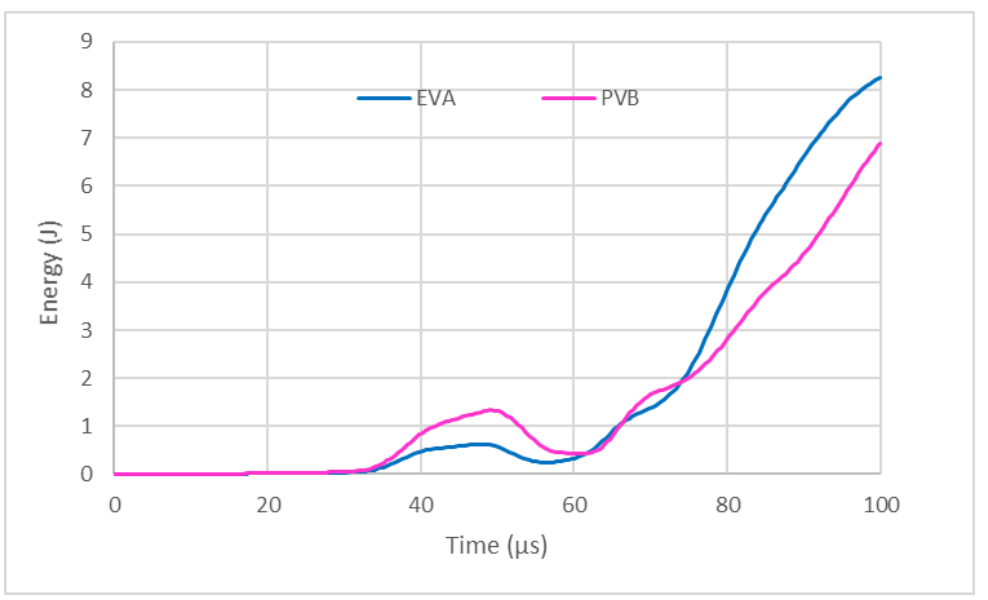

Figure. 28. Energy time history for laminate glass plate subjected to spherical impactor.

\section{Discussion and Conclusion}

In this study, impact response of laminated glass plate, subjected drop weight, was studied by using the finite element method. Commercial finite element package program ABAQUS was used in the study. 3D finite element model is developed to analyze the effect of impactor geometry and interlayer type on the impact response of laminated glass plate. In the current study analysis are carried out for velocities between $0-50 \mathrm{~m} / \mathrm{s}$. This means in this study low velocities are considered. Impact responses of principal stress and displacement were investigated for impact parameters like velocity, impactor geometry and interlayer type.

From the conducted analysis it is observed that impactor geometry, interlayer type and velocity are factors which affect the impact behavior of laminated glass unit.

The conclusions obtained from this investigation are:

- Stress and displacement values of laminated unit bonded by EVA greater than those of PVB.

- Laminated glass unit subjected to cylindrical impactor absorbs more internal energy than those of subjected to spherical impactor.

- Geometry of impactor is an important factor affects the character of displacement- time history curves.

- Displacement and stress of laminated glass unit significantly increase with increasing impact velocity.

- Character of displacement- time history curves is depend on the geometry of impactor

\section{Acknowledgement}

This work has been funded by the Adnan Menderes University Department of Scientific Research Council, Turkey.

\section{References}

Aşık, M.Z. (2003). Laminated glass plate: revealing of nonlinear behavior. Computers and Structures, 81, $2659-2671$. doi:0.1016/S0045-7949(03)00325-0 
Aşık, M.Z. \& Tezcan, S. (2005). A mathematical model for the behavior of laminated glass beams. Computers and Structures, 83, 1742-1753. doi:10.1016/j.compstruc.2005.02.020

Behr, R. A., Kremer, P. A., Dharani L. R., Ji F. S. \& Kaiser N. D. (1999). Dynamic strains in architectural laminated glass subjected to low velocity impacts from small projectiles. Journal of Materials Science, 34, 5749-5756. doi:10.1023/A:1004702100357

Behr, R.A. \& Kremer, P.A. (1996) Performance of Laminated Glass Units under Simulated Windborne Debris Impacts. Journal of Architectural Engineering, 2(3 ), 95-99. doi: 10.1061/(ASCE)1076-0431

Behr, R.A., Minor, J.E., Linden, M.P. \& Vallabhan, C. V. G. (1985).Laminated glass units under uniform lateral pressure. Journal of Structural Engineering, 111(5), 1037-1050. doi: 10.1061/(ASCE)0733-9445(1985)111:5(1037)

Behr, R.A., Minor, J.E. \& Norville, H.S. (1993). Structural behavior of architectural laminated glass. Journal of Structural Engineering, 119(1), 202-222. doi: 10.1061/(ASCE)0733-9445(1993)119:1(202)

Behr, R.A., Linden, M.P. \& Minor, J.E. (1986). Load duration and interlayer thickness effects on laminated glass. Journal of Structural Engineering, 112(6), 1441-1453. https://doi.org/10.1061/(ASCE)0733-9445(1986)112:6(1441)

Flocker, F.W. \& Dharani, L.R. (1997) Stresses in laminated glass subject to low velocity impact. Engineering Structures, 19( 10), 851-856. doi: 10.1016/S0141-0296(97)00162-4

Foraboschi, P. (2012). Analytical model for laminated-glass plate. Compo Part B: Eng., 43(5), 2094-2106 .doi: 10.1016/j.compositesb.2012.03.010

Foraboschi, P. (2007). Behavior and Failure Strength of Laminated Glass Beams. Journal of Engineering Mechanics, 133 (12), 1290-1301. doi:10.1061/(ASCE)0733-9399(2007)133:12(1290)

Galuppi, L. \& Royer-Carfagni, G. (2012). Laminated beams with viscoelastic interlayer. Int. J. Solid Struct., 49, 2637-2645. doi: 10.1016/j.ijsolstr.2012.05.028

Hooper, J.A. (1973). On the bending of architectural laminated glass. Int. J. Mech. Sci., 15, 309-323. doi: 10.1016/00207403(73)90012-X

Karanurathna, K.A. (2013). Low -Velocity Impact Analysis of Monolithic and Laminated Glass Using Finite Element Method, MS Thesis, University of Birmingham, Birmingham, United Kingdom.

Kim, S.J., Goo, N.S. \& Kim, T.W. (1997). The effect of curvature on the dynamic response and impact-induced damage in composite laminates. Compos Sci Technol, 51, 763-73. doi: 10.1016/S0266-3538(97)80015-2

Liu, Y. \& Liaw, B. (2009). Drop-weight impact tests and finite element modeling of cast acrylic plates. Polymer Testing, 28, 599611. doi:10.1016/j.polymertesting.2009.04.008

Minor, J. E. \& Reznik, P. L. (1990). Failure Strength of Laminated Glass. Journal of Structural Engineering ASCE, 116(4), 10301039. doi:10.1061/(ASCE)0733-9445(1990)116:4(1030)

Pantelides, C. P., Horst, A. D. \& Minor, J. E. (1993). Postbreakage Behavior of Heat Strengthened Laminated Glass under Wind Effects J. Struct. Eng., 119(2), 2425-2435. doi: 10.1061/(ASCE)0733-9445(1993)119:2(454)

Saxe, T.J., Behr, R.A., Minor, J.E., Kremer, P.E. \& Dharani, L.R. (2002). Effects of Missile Size and Glass Type on Impact Resistance of "Sacrificial Ply" Laminated Glass. Journal of Architectural Engineering, 8(1), doi: 10.1061/(ASCE)10760431(2002)8:1(24)

Timmel, M., Kolling, S., Osterrieder, P. \& Du Bois, P.A. (2007). A finite element model for impact simulation with laminated glass. International Journal of Impact Engineering, 34(8), 1465-1478. doi:10.1016/j.ijimpeng.2006.07.008

Vallabhan, C.V.G., Das, Y.C. , Magdi, M. \& Asik M.Z. (1993). Analysis of laminated glass units. Journal of Structural Engineering, 119(5), 1572-1585. doi: 10.1061/(ASCE)0733-9445(1993)119:5(1572)

Yuan, Y., Xu, C., Xu, T., Sun, Y., Liu, B. \& Li, Y. (2017). An analytical model for deformation and damage of rectangular laminated glass under low-velocity impact. Composite Structures, 176, 833-843.

http://dx.doi.org/10.1016/j.compstruct.2017.06.029

Wang, X., Yang, J., Liu, Q., Zhang, Y. \& Zhao, C. (2017). A comparative study of numerical modelling techniques for the fracture of brittle materials with specific reference to glass. Engineering Structures, 152, 493-505

https://doi.org/10.1016/j.engstruct.2017.08.050 